\title{
Root to Shoot Relations in an Annual Raspberry (Rubus idaeus L.) Production System
}

\author{
Horacio E. Alvarado-Raya, Rebecca L. Darnell ${ }^{1}$, \\ and Jeffrey G. Williamson \\ Horticultural Sciences Department, University of Florida, P.O. Box 110690, \\ Gainesville, FL 32611
}

Additional index words. girdling, photosynthesis, protected agriculture, tunnel production

\begin{abstract}
Low yields have been observed in annual production systems in raspberry (Rubus idaeus $\mathbf{L}$.) compared with annual yields in perennial systems. This yield reduction could be related to a depletion of root carbohydrates and its consequent detrimental effect on fruit number or size. Additionally, primocanes could play an important role in the carbohydrate dynamics in an annual system and may also affect yield. Two experiments were carried out in 2003 and 2004 to determine the importance of root carbohydrates and primocanes in fruiting and yield components of 'Tulameen' red raspberry in an annual production system. In the 2003 experiment, girdled floricanes were compared with nongirdled controls. Girdling before bloom decreased fruits per cane and consequently yield per cane compared with controls, whereas girdling at the end of bloom had no effect. Root dry weight accumulation at the end of the fruiting season was significantly less in both early and late girdled compared with nongirdled plants. In 2004, floricanes were completely girdled or nongirdled at midflowering. Additionally, three primocanes were permitted to grow in one-half of the nongirdled and girdled plants, whereas primocanes were completely removed from the other half. Girdling and removal of all primocanes resulted in $100 \%$ plant mortality. In the presence of primocanes, floricane girdling had no effect on yield compared with the nongirdled treatments. There was a reduction in root dry weight in the nongirdled + primocane removal treatment compared with the treatments in which three primocanes were present. In the presence of primocanes, however, root dry weights were similar in both girdled and nongirdled plants. These results suggest that root carbohydrates are important in determining fruit number and yield in the annual system, and reductions in root carbohydrate during early flowering results in decreased yield. However, roots appear to quickly convert from source to sink status, and as the season progresses, both floricanes and primocanes act as sources to replenish root carbohydrate reserves. Carbohydrate dynamics appear to be similar between the annual production system and the traditional perennial system; however, because the annual system begins with limited carbohydrate reserves resulting from root pruning that occurs during removal from the nursery, yields are lower than those seen in perennial systems.
\end{abstract}

Interest in off-season production of red raspberry (Rubus idaeus L.) is increasing as a result of the high demand for a limited supply (Darnell et al., 2006; Knight et al., 1996; Pritts et al., 1999; Schloemann, 2001) and the resultant increase in returns for producers (Pritts et al., 1999). Several systems for offseason production of raspberry have been examined, including annual planting systems (Darnell et al., 2006; Knight et al., 1996). In these systems, long cane plants are removed from northern nurseries in early winter, shipped, and planted immediately in warm winter areas. After fruiting, plants are removed and discarded, and new plants are replanted the next winter. Yield per cane obtained in these systems is similar to firstyear yields in perennial production systems

Received for publication 16 May 2007. Accepted for publication 24 June 2007.

${ }^{1}$ To whom reprint requests should be addressed; e-mail rld@ufl.edu. carbohydrates play an important role in supplying carbohydrates to floricanes during budbreak and early flowering (Fernandez and Pritts, 1993; Oliveira et al., 2007) and therefore can significantly impact cane yield (Rangelov et al., 1998). This is especially true when current carbohydrate availability is limited (Fernandez and Pritts, 1996). The continuous production of new primocanes also generates a sink for root carbohydrates (Whitney, 1982) until the new primocane leaves become photosynthetically competent. At this point, current photosynthate from primocanes is mobilized to the apices to support further vegetative growth and to roots for storage (Fernandez and Pritts, 1993). It is primarily through carbon mobilization from the primocanes that the root carbohydrate pool is replenished (Whitney, 1982), although mobilization from floricanes to roots has also been shown (Fernandez and Pritts, 1993).

There appears to be substantial growth competition between primocanes and floricanes. Primocane removal often increases yield compared with plants in which primocanes are maintained during the fruiting season (Dalman, 1989; Wright and Waister, 1982a). Conversely, primocane number increases significantly when floricanes (or inflorescences) are removed (Vasilakakis and Dana, 1978; Wright and Waister, 1982b). Previous work indicates there is little current photosynthate translocated from floricanes to primocanes (and vice versa) (Fernandez and Pritts, 1993), and the authors suggested that light competition, rather than carbohydrate competition, is responsible for the growth competition observed between floricanes and primocanes. However, the results were limited in scope, addressing only current photosynthate translocation from a single labeled leaflet and did not address mobilization and partitioning of stored carbohydrate from roots to floricanes and primocanes. Dalman (1989) concluded that root storage carbohydrates are important for both floricane and primocane development, and limitations in the root carbohydrate pool decreased yield or primocane growth, depending on when the limitation occurred. Thus, although there may be little direct translocation of carbohydrate from primocanes to floricanes and vice versa, there appears to be competition for root carbohydrates by both primocanes and floricanes.

As indicated, roots act as a carbohydrate source for early reproductive growth of floricanes and early vegetative growth of primocanes (Fernandez and Pritts, 1994; Whitney, 1982). Later in the growing season, roots act as a sink, obtaining carbohydrates from both floricanes and primocanes (Fernandez and Pritts, 1993). Therefore, understanding carbohydrate partitioning patterns among primocanes, floricanes, and roots is crucial for the successful implementation of an annual production system as described. The reduction in root biomass when plants are removed from the nursery would be expected to decrease the root carbohydrate pool and may alter carbohydrate dynamics in 
an annual production system compared with the traditional perennial system.

The objectives of the present study were to determine the influence of root carbohydrates and the presence or absence of primocanes on yield in an annual raspberry production system. Two experiments were designed to meet the objectives. In the first experiment (2003), floricanes were girdled at one of two times during bloom to determine the role and timing of root carbohydrates as a source for fruit development. Cane girdling, which interrupts assimilate translocation in the phloem, is a useful but rarely used technique for examining source-sink relations in raspberry (Prive et al., 1994). In 2004, the effects of floricane girdling during bloom in the presence or absence of primocanes was examined to further determine the role and timing of root and primocane source-sink dynamics on yield in the annual production system.

\section{Materials and Methods}

2003 experiment. Dormant bare-root long canes $(\approx 1.5 \mathrm{~m})$ of 'Tulameen' red raspberry were purchased in Fall 2002 from a nursery in the Pacific northwestern United States and chilled for $1220 \mathrm{~h}$ at $7^{\circ} \mathrm{C}$. Canes were planted on 18 Dec. 2002 at $50 \mathrm{~cm}$ in-row and $180 \mathrm{~cm}$ between rows in a two-bed system inside a polyethylene tunnel as described previously (Darnell et al., 2006). The beds were filled with a soiless mixture of perlite, peat, and bark $(60: 15: 25)$ to a depth of $25 \mathrm{~cm}$. Canes were watered at a rate of $\approx 2.0 \mathrm{~L} /$ day and fertilized weekly with $20 \mathrm{~N}-8.8 \mathrm{P}-16.6 \mathrm{~K}$ water-soluble fertilizer (J.R. Peters, Inc., Allentown, PA) at a rate of $0.6 \mathrm{~g} / \mathrm{plant}$ nitrogen. Three primocanes were allowed to grow during the growing season and the remaining primocanes were removed when they reached 20 to $30 \mathrm{~cm}$ in length.

Floricanes were girdled two times during bloom and compared with a nongirdled control. Complete $(100 \%)$ girdling was done at $10 \mathrm{~cm}$ above the media level by removing a 3-mm strip of bark (epidermis, cortex, and phloem) around the entire circumference of the cane with a knife. Early girdling was done $\approx 16 \mathrm{~d}$ before bloom [6 Feb. 2003, $50 \mathrm{~d}$ after planting (DAP)] and late girdling was done when $\approx 80 \%$ of the flowers had opened (12 Apr. 2003, 115 DAP). Captan 50WP $\left(0.5 \mathrm{~g} \cdot \mathrm{L}^{-1}\right)$ was sprayed on the girdled zone immediately after girdling.

Ripe fruit were harvested at 2-d intervals, weighed, and dried at $80{ }^{\circ} \mathrm{C}$ until constant weight. Fruits harvested at peak of harvest were frozen and stored at $-20{ }^{\circ} \mathrm{C}$ for quality analysis. At the end of the fruiting season (152 DAP for nongirdled, 167 DAP for early girdled, and 162 DAP for late-girdled plants), plants were divided into roots, floricane stems, floricane laterals, and primocanes and fresh weights obtained. Plant parts were dried at $80{ }^{\circ} \mathrm{C}$ until constant weight.

Fruits used for quality measurements were homogenized in a mortar and pestle and filtered through three layers of cheese- cloth. Juice was centrifuged for $20 \mathrm{~min}$ at $2000 \times g$ and the supernatant decanted. Fruit soluble solids were determined with a refractometer (Atago PR-101, Tokyo). Total titratable acidity was determined as percent of citric acid by diluting $6 \mathrm{~mL}$ of the supernatant with $50 \mathrm{~mL}$ distilled water and titrating with $0.1 \mathrm{~N} \mathrm{NaOH}$ to a final $\mathrm{pH}$ of 8.2. Milliliters of $\mathrm{NaOH}$ were recorded and titratable acidity (as citric acid equivalents) was calculated as described by Garner et al. (2003) with a millequivalent factor of 0.064 for citric acid.

The three treatments (nongirdled control, early girdling, and late girdling) were arranged in the tunnel in a completely randomized design. There were six replications per treatment and one plant was considered as the experimental unit. Late-girdled plants were not analyzed for flowering and fruiting time, because these treatments were applied after flowering and fruiting began. Yield components, dry weight allocation, and fruit quality data were analyzed for all three treatments.

2004 experiment. 'Tulameen' bare-root long canes purchased in mid-Jan. 2004 were chilled for $1290 \mathrm{~h}$ at $7^{\circ} \mathrm{C}$. On 11 Mar., canes were individually planted in black polyethylene containers (36.7-L capacity; Olympia C4000; Nursery Supplies, Fairless Hills, PA) containing a mixture of coir, perlite, and peat (1:3:1) and placed inside a polyethylene tunnel (Darnell et al., 2006). Canes were hand-watered at a rate of $\approx 2.0 \mathrm{~L} /$ day and fertilized as described previously.

On 10 May 2004 (62 DAP; peak of flowering), 24 floricanes were selected for uniformity in height and vigor. Half of the floricanes were completely girdled as described previously and half of the floricanes remained as the nongirdled controls. At the same time, primocanes were removed in half of each of the girdled and nongirdled treatment plants. The remaining plants were allowed to grow three primocanes each. New primocanes in all plants were removed continuously throughout the experiment. Like in the previous experiment, Captan 50WP was sprayed on the girdled zone.

Net photosynthesis $(\mathrm{Pn})$ was determined by measuring the $\mathrm{CO}_{2}$ assimilation rate in floricane and primocane leaves with a portable gas exchange analyzer (LI-COR LI-6400; Lincoln, NE). The uppermost fruiting laterals in the top, middle, and lower sections of each floricane were selected and Pn was measured on the fully open distal leaf of each lateral. Data from the three sections in each floricane were pooled to determine the floricane Pn. In primocanes, the uppermost fully open leaf was selected and Pn was determined on the distal leaflet. Plants were watered $(2 \mathrm{~L} /$ pot $)$ the day before $\mathrm{CO}_{2}$ measurements. Photosynthesis was measured between 0900 and $1100 \mathrm{HR}$ ( 2.5 to $4.5 \mathrm{~h}$ after sunrise) every week from the peak of fruiting (2 June 2004; 85 DAP) through 24 June 2004 (107 DAP) when $80 \%$ of fruits had been harvested. Average leaf temperatures during measurements ranged from $29^{\circ} \mathrm{C}$ on 2 June to $33{ }^{\circ} \mathrm{C}$ on 24 June. Average light intensity ranged from 1000 to 1500 photosynthetic photon flux $(P P F)$, above the light saturation point of 500 to 700 PPF (Fernandez and Pritts, 1994).

Ripe fruit were harvested as described previously and fruit quality analyses were done. At the end of fruit harvest, plants were harvested as described previously. Average final fruit harvest and plant harvest times were 109 DAP $(\approx 25$ June $)$ for the girdled + primocane treatment, 115 DAP ( $\approx 2$ July) for the nongirdled + primocane treatment, and 118 DAP ( $\approx 5$ July) for the nongirdled without primocane treatment.

The experiment was initially set up as a $2 \times 2$ factorial (girdling versus no girdling and primocanes versus primocane removal) in a randomized complete block design (RCBD) with cane vigor and diameter used as block determinants. There were six replications per treatment and one plant (pot) was considered an experimental unit. In this experiment, all girdled canes without primocanes died within $20 \mathrm{~d}$ of girdling and they were not considered for further analysis. Remaining treatments were 1) nongirdled canes with primocanes (control), 2) nongirdled canes without primocanes, and 3) girdled canes with primocanes. Data from these three treatments were analyzed as a RCBD. In both 2003 and 2004 experiments, all data except for photosynthetic measurements were analyzed by using the GLM procedure in SAS (SAS institute Inc., Cary, NC). Photosynthetic data were analyzed as repeated measures using the MIXED procedure.

\section{Results}

2003 experiment. The effect of girdling time on flowering could not be assessed, because late girdling was done $25 \mathrm{~d}$ after peak of bloom. There was little effect of early girdling on flowering time. The end of flowering was slightly delayed in the early girdling compared with the control (146 DAP versus 143 DAP, $P=0.01)$. Early girdling decreased the flowering period by $10 \mathrm{~d}(86$ versus $76 \mathrm{~d}$ for early girdling and control, respectively); however, the decrease was not statistically significant $(P=0.08)$. There were no significant differences among treatments in the beginning, ending, or length of the fruit harvest period. Fruit harvest began 22 Mar. 2003 (94 DAP) and peaked $\approx 19$ Apr. (122 DAP) with final harvest occurring the latter part of May.

Early girdling significantly decreased fruits per cane and yield per cane compared with the nongirdled control (Table 1). There was no significant effect of late girdling on any yield component.

At the end of the fruiting season, root dry weight in early girdled floricanes was significantly lower than root dry weight of the nongirdled canes (Table 2). Early girdling also decreased total fruit dry weight compared with the nongirdled control, reflecting the significant decrease in fruit number. Late girdling decreased root dry weight, but had no effect on final dry weight of any other organ. 
Early girdling decreased fruit soluble solids $(11.3 \%)$ compared with the nongirdled control $(12.2 \%)$ and the late-girdled canes $(13.1 \%)(P=0.05)$. There was no effect of girdling on fruit titratable acidity $(\approx 2.4 \%)$, the ratio of soluble solids:titratable acidity $(\approx 5.0)$, or $\mathrm{pH}(\approx 3.6)$.

2004 experiment. No data were taken for the beginning of flowering in the 2004 experiment. However, flowering ended $\approx 18 \mathrm{~d}$ earlier in girdled compared with nongirdled canes, regardless of the presence of primocanes (91 versus 109 DAP, respectively, $P \leq$ $0.01)$. Treatments did not significantly affect the beginning, ending, or length of the fruiting period. Fruit harvest began 22 May 2004 (72 DAP) and ended in early July. Fruit harvest occurred later in 2004 than in 2003 as a result of the later planting date.

There was little effect of treatment on yield components (Table 1). There was also little treatment effect on dry weight allocation, except for a reduction in root dry weight in the nongirdled + primocane removal treatment compared with the treatments in which three primocanes were present (Table 2). Total plant dry weight was also significantly reduced in the primocane removal treatment.

There were no treatment effects on any fruit quality parameters. Fruit soluble solids averaged $11.7 \%$ and titratable acidity averaged $2.4 \%$.

Primocane leaf photosynthesis averaged $9.5 \mu \mathrm{mol} \cdot \mathrm{m}^{-2} \cdot \mathrm{s}^{-1}$, significantly greater than floricane leaf photosynthesis, which averaged $6.6 \mu \mathrm{mol} \cdot \mathrm{m}^{-2} \cdot \mathrm{s}^{-1}(P<0.001)$. There were no significant differences in leaf photosynthesis between girdled and nongirdled canes at any date, nor was floricane photosynthesis affected by the presence or absence of primocanes. There was, however, a significant interaction between cane type and date on leaf photosynthesis (Table 3). Floricane leaf photosynthesis declined as fruit ripening progressed, whereas primocane leaf photosynthesis remained steady before decreasing at the end of fruit harvest.

\section{Discussion}

Because girdling times in 2003 and 2004 occurred at different phenological stages (before bloom and near the end of bloom in 2003; peak of bloom in 2004), direct comparison of girdling effects between the 2 years was not possible. However, girdling effects on the flowering time differed between years; delaying the end of flowering slightly in 2003 while significantly advancing the end of flowering in 2004 compared with the nongirdled control. Although differences in the flowering period between years would be expected as a result of environmental differences, one would expect the flowering response to girdling versus nongirdling to be similar in both years. It is unclear why the response between years was different. Temperatures were lower during bloom in 2003 compared with 2004, averaging $26 / 18{ }^{\circ} \mathrm{C}$ day/night versus $29 / 20^{\circ} \mathrm{C}$ day/night, respectively. Additionally, the planting regimes

Table 1. Yield components for Tulameen red raspberry as affected by girdling time (2003) or girdling and primocane removal (2004) in an annual production system $(n=6)$.

\begin{tabular}{lcccc}
\hline & $\begin{array}{c}\text { Flowers } \\
\text { per cane }\end{array}$ & $\begin{array}{c}\text { Fruits } \\
\text { per cane }\end{array}$ & $\begin{array}{c}\text { Yield/cane } \\
(\mathrm{g} \text { fresh weight })\end{array}$ & $\begin{array}{c}\text { Fruit } \\
\text { size }(\mathrm{g})\end{array}$ \\
\hline Treatment & $2003^{\mathrm{z}}$ & & & \\
$\quad$ Nongirdled & & & & \\
$\quad$ Early girdling & & & & \\
Late girdling & 106.5 & $45.2 \mathrm{a}^{\mathrm{y}}$ & $91.3 \mathrm{a}$ & 2.10 \\
$P$ value & 70.2 & $15.0 \mathrm{~b}$ & $23.2 \mathrm{~b}$ & 1.83 \\
& 56.0 & $31.8 \mathrm{ab}$ & $64.6 \mathrm{a}$ & 1.96 \\
Treatment & 0.09 & 0.02 & 0.01 & 0.40 \\
$\quad$ Nongirdled + three primocanes & 2004 & & & \\
Nongirdled + primocane removal & 180.0 & 60.0 & 160.4 & 2.65 \\
Girdled + three primocanes & 164.8 & 64.5 & 145.6 & 2.27 \\
$P$ value & 139.8 & 50.8 & 116.9 & 2.31 \\
\hline
\end{tabular}

${ }^{2}$ Three primocanes were present on all girdled and control plants in the 2003 experiment.

y Least-squares mean separation by Tukey at the indicated $P$ value.

${ }^{x}$ Early girdling (100\%) was done on 6 Feb. 2003 [50 d after planting (DAP); before bloom] and late girdling $(100 \%)$ was done on 12 Apr. 2003 (115 DAP; end of bloom) at $10 \mathrm{~cm}$ above media level.

${ }^{\mathrm{w}}$ Girdling $(100 \%)$ and primocane removal were done on 10 May 2004 (62 DAP; peak of flowering).

Table 2. Dry weight partitioning in Tulameen red raspberry as affected by girdling time (2003) or girdling and primocane removal (2004) in an annual production system $(\mathrm{n}=6)$.

\begin{tabular}{|c|c|c|c|c|c|c|}
\hline & \multicolumn{6}{|c|}{ Dry wt $(\mathrm{g})$} \\
\hline & Primocane & Roots & $\begin{array}{c}\text { Floricane } \\
\text { stem }\end{array}$ & $\begin{array}{c}\text { Floricane } \\
\text { laterals }\end{array}$ & Fruits & Total \\
\hline \multicolumn{7}{|c|}{$2003^{z}$} \\
\hline \multicolumn{7}{|l|}{ Treatment } \\
\hline Nongirdled & 181.3 & $91.3 \mathrm{a}^{\mathrm{y}}$ & 18.3 & 15.0 & $14.4 \mathrm{a}$ & 307.6 \\
\hline Early girdling ${ }^{\mathrm{x}}$ & 118.7 & $62.2 \mathrm{~b}$ & 21.3 & 11.9 & $2.8 \mathrm{~b}$ & 220.3 \\
\hline Late girdling & 160.7 & $71.8 \mathrm{~b}$ & 20.4 & 10.4 & $12.8 \mathrm{a}$ & 273.9 \\
\hline$P$ value & 0.06 & 0.006 & 0.75 & 0.67 & 0.01 & 0.08 \\
\hline \multicolumn{7}{|c|}{2004} \\
\hline Treatment & & & & & & \\
\hline Nongirdled + three primocanes ${ }^{\mathrm{w}}$ & 35.4 & $32.9 \mathrm{a}$ & 29.8 & 32.5 & 24.1 & $154.8 \mathrm{a}$ \\
\hline Nongirdled + primocane removal & - & $26.4 \mathrm{~b}$ & 30.7 & 29.2 & 24.6 & $111.0 \mathrm{~b}$ \\
\hline Girdled + three primocanes & 39.1 & $35.2 \mathrm{a}$ & 32.1 & 27.5 & 17.8 & $151.7 \mathrm{a}$ \\
\hline$P$ value & 0.15 & 0.005 & 0.35 & 0.54 & 0.10 & 0.003 \\
\hline
\end{tabular}

${ }^{2}$ Three primocanes were present on all girdled and control plants in the 2003 experiment.

y Least-squares mean separation by Tukey at the indicated $P$ value.

${ }^{x}$ Early girdling (100\%) was done on 6 Feb. 2003 [50 d after planting (DAP); before bloom] and late girdling (100\%) was done on $12 \mathrm{Apr} .2003$ (115 DAP; end of bloom) at $10 \mathrm{~cm}$ above media level.

${ }^{\mathrm{w}}$ Girdling (100\%) and primocane removal were done on 10 May 2004 (62 DAP; peak of flowering).

differed between years (raised beds in 2003 versus containers in 2004). These differences or others may have altered the flowering response to girdling versus nongirdling.

In 2003, early girdling decreased fruit yield (fresh weight) and total fruit dry weight compared with no girdling. This decrease appears attributable to decreased fruit number rather than decreased fruit size, although the decrease in fruit load in girdled canes may have masked any detrimental effects of girdling on fruit size. It is likely that early girdling in the 2003 experiment prevented translocation of carbohydrates from roots, which are the main source of carbon for floricanes during budbreak (Fernandez and Pritts, 1994). This would limit carbohydrate availability for reproductive development, leading to a decrease in fruit number and yield per cane. Later girdling, both in 2003 and 2004, had less of an effect on fruit number, indicating that once the floricane lateral leaves became carbohydrate sources, roots were less important for fruit set and development. This is supported by previous work indicating that once floricane laterals develop, they become the main assimilate source for fruits (Fernandez and Pritts, 1993;
Table 3. Net photosynthesis in floricane and primocane leaves of Tulameen red raspberry at weekly intervals during fruiting in $2004(\mathrm{n}=12)$.

\begin{tabular}{ccccc}
\hline & \multicolumn{4}{c}{$\begin{array}{c}\text { Leaf net photosynthesis } \\
\left(\mu \mathrm{mol} \cdot \mathrm{m}^{-2} \cdot \mathrm{s}^{-1}\right)\end{array}$} \\
\cline { 2 - 5 } & \multicolumn{4}{c}{ Days after planting } \\
\cline { 2 - 5 } & 85 & 92 & 100 & 107 \\
\hline Cane type & & & & \\
Floricane & $9.1 \mathrm{ab}^{\mathrm{z}}$ & $6.6 \mathrm{c}$ & $7.2 \mathrm{bc}$ & $3.5 \mathrm{~d}$ \\
Primocane & $11.0 \mathrm{a}$ & $11.0 \mathrm{a}$ & $9.9 \mathrm{a}$ & $6.2 \mathrm{c}$ \\
\hline
\end{tabular}

${ }^{\mathrm{z}}$ Means across days and cane type followed by different letters are different at $P<0.05$ by least squares means.

Prive et al., 1994). However, in the present study, the trend toward decreased yield in later-girdled plants in both 2003 and 2004 suggest that although laterals are the main assimilate source for fruits, they may not be the sole source and roots may still supply carbohydrates, especially if current carbohydrate supply is limited (Fernandez and Pritts, 1996).

Primocane removal in 2004 had little effect on yield components in nongirdled plants, although, as indicated previously, primocane removal in conjunction with girdling resulted in $100 \%$ plant mortality. This suggests that with an intact root system, 
primocanes and floricanes act independently of each other (Fernandez and Pritts, 1993), and roots act initially as a carbohydrate source for both. However, root carbohydrates must be replenished and both floricanes and primocanes can act as carbohydrate sources for roots (Fernandez and Pritts, 1993; Whitney, 1982). Thus, plant death in the girdled canes in which primocanes were also removed was likely the result of lack of carbohydrate import from floricanes and primocanes, which limited basic root metabolism (e.g., water and nutrient uptake), resulting in plant death.

The transition of raspberry roots from source to sink occurs during the onset of fruiting (Fernandez and Pritts, 1994; Whitney, 1982). In our study, root dry weight decreased in both early and late girdling treatments in 2003; however, girdling had no effect on root dry weight in the 2004 experiment. This suggests that in 2003, floricanes were an important source for replenishment of root carbohydrate reserves. The early girdling initially disrupted translocation when roots were acting as a source for floricanes, resulting in a decrease in yield. However, the girdle was still in place when roots underwent transition from source to sink, and the decrease in root dry weight suggests that floricanes were an important source for root carbohydrate replenishment during this time. The late girdle occurred after the roots transitioned from source to sink, disrupting carbohydrate translocation from floricanes to roots, also resulting in a decrease in root dry weight. In 2004, however, girdling at peak of bloom did not affect root dry weight, suggesting that floricanes were not acting as a carbohydrate source for roots. The reduction of root dry weight in response to primocane removal indicates that primocanes were the primary source for root carbohydrates. Thus, it appears that floricanes were far less important as carbohydrate sources to roots in the 2004 experiment compared with the 2003 experiment. This may have been the result of the greater reproductive load in 2004 compared with 2003, which constituted a strong sink for floricane carbohydrates. Fruit may have outcompeted the roots for floricane carbohydrates and limited carbohydrate translocation from the floricanes to the root in the 2004 experiment. In this scenario, floricane girdling after roots transitioned from source to sink would have had negligible effects on root dry weight, because floricane carbohydrates in both girdled and nongirdled floricanes were being used almost solely by developing fruit.
The lack of a girdling effect on floricane leaf photosynthesis supports the suggestion that fruits were the primary sink at the time of girdling in 2004, because it might be expected that if roots were also a sink, eliminating root carbohydrate demand would decrease photosynthesis (Zhou and Quebedeaux, 2003). The general decline in floricane leaf photosynthesis during fruiting may have been the result of a combination of decreased sink demand as fruit was harvested, increased temperature, or increasing leaf age, because all floricane leaves develop in the spring (Fernandez and Pritts, 1994).

In conclusion, the decrease in yield observed in girdled versus nongirdled floricanes in 2003 indicates that girdling prevented root carbohydrate translocation to the floricane during the early part of the flowering period, resulting in a decrease in fruit number and yield. Roots undergo transition to sinks later in the flowering season, and it appears that both floricanes and primocanes act as carbon sources for roots; however, the extent of the contribution from floricanes may depend on the fruit load. There does not appear to be direct carbohydrate translocation between primocanes and floricanes, because primocane removal did not affect dry weight accumulation in floricanes. Our results support the idea that roots act as both a source and a sink in the annual production system as they do in the traditional perennial system. However, roots in the annual system likely have lower carbohydrate reserves than roots in the perennial system as a result of root pruning when canes are removed from the nursery on an annual basis. Thus, it appears that the lower yields reported in the annual system compared with the perennial system (Darnell et al., 2006) may be the result of an overall decrease in root carbohydrate reserves in the annual system, and not differences in source-sink relationships between the two production systems. Further work on the effects of root pruning on raspberry carbohydrate dynamics and yield is warranted.

\section{Literature Cited}

Crandall, P.C. 1995. Bramble production. The management and marketing of raspberries and blackberries. Food Products Press, Binghamton, NY.

Dalman, P. 1989. Within-plant competition and carbohydrate economy in the red raspberry. Acta Hort. 262:269-276.

Darnell, R.L., B. Brunner, H.E. Alvarado, J.G. Williamson, M. Plaza, and E. Negron. 2006. Annual, off-season raspberry production in warm season climates. HortTechnology 16: 92-97.

Fernandez, G.E. and M.P. Pritts. 1993. Growth and source-sink relationships in 'Titan' red raspberry. Acta Hort. 352:151-157.

Fernandez, G.E. and M.P. Pritts. 1994. Growth, carbon acquisition, and source-sink relationships in 'Titan' red raspberry. J. Amer. Soc. Hort. Sci. 119:1163-1168.

Fernandez, G.E. and M.P. Pritts. 1996. Carbon supply reduction has a minimal effect influence on current year's red raspberry (Rubus idaeus L.) fruit production. J. Amer. Soc. Hort. Sci. 121:473-477.

Garner, D., C.H. Crisosto, P. Wiley, and G.M Crisosto. 2003. Measurement of $\mathrm{pH}$ and titratable acidity. 16 May 2007. <http://www. uckac.edu/postharv/PDF\%20files/Guidelines/ quality.pdf $>$.

Knight, R.J., J.H. Crane, H.H. Bryan, W. Klassen, and B. Schaffer. 1996. The potential of autumnbearing red raspberries as an annual crop in Florida. Proc. Fla. State Hort. Soc. 109:231232.

Oliveira, P.B., M.J. Silva, R.B. Ferreira, C.M Oliveira, and A.A. Monteiro. 2007. Dry matter partitioning, carbohydrate composition, protein reserves, and fruiting in 'Autumn Bliss' red raspberry vary in response to pruning date and cane density. HortScience 42:77-82.

Pritts, M.P., R.W. Langhans, T.H. Whitlow, M.J. Kelly, and A. Roberts. 1999. Growing winter raspberries in a greenhouse. HortTechnology 9:13-15.

Prive, J.P., J.A. Sullivan, and J.T.A. Proctor. 1994. Carbon partitioning and translocation in primocane-fruiting red raspberry (Rubus idaeus L.). J. Amer. Soc. Hort. Sci. 119:604-609.

Rangelov, B., T. Petkov, and M. Nesheva. 1998. Carbon nutrition of summer fruiting raspberry cultivars - transport of $14 \mathrm{C}$ - assimilates from root to fruit. Bulgarian J. Agr. Sci. 4: 763-766.

Schloemann, S. 2001. Greenhouse raspberry production for winter sales. 16 May 2007. $<$ http://www.umass.edu/fruitadvisor/factsheets/ greenhouserasp/raspberriesgh.htm>.

Vasilakakis, M.D. and M.N. Dana. 1978. Influence of primocane inflorescence removal on number of inflorescences and suckers in 'Heritage' red raspberry. HortScience 13:700-701.

Whitney, G.G. 1982. The productivity and carbohydrate economy of a developing stand of Rubus idaeus. Can. J. Bot. 60:2697-2703.

Wright, C.J. and P.D. Waister. 1982a. Within-plant competition in the red raspberry. II. Fruiting cane growth. J. Hort. Sci. 57:443-448.

Wright, C.J. and P.D. Waister. 1982b. Within-plant competition in the red raspberry. I. Primocane growth. J. Hort. Sci. 57:437-442.

Zhou, R. and B. Quebedeaux. 2003. Changes in photosynthesis and carbohydrate metabolism in mature apple leaves in response to whole plant source-sink manipulation. J. Amer. Soc. Hort. Sci. 128:113-119. 